\title{
Formation Manner of Monotectic Structure in Al-In Alloys Solidified Unidirectionally*
}

\author{
By Akihiko Kamio**, Hiroyasu Tezuka**, Shinji Kumai*** \\ and Tsuneo Takahashi**
}

\begin{abstract}
Monotectic Al-17.5 mass\%In alloys were solidified unidirectionally at various growth rates and temperature gradients, and were quenched during growth to reveal the solid-liquid interface morphology. The alloys having fibrous composite structures were held near the monotectic temperature for various time durations to examine the thermal stability of $L_{2}$ fibers. When fibrous composite structures are forming, the planar solid-liquid interface proceeds with some projections of $L_{2}$ phase toward $L_{1}$. Periodical fluctuation of the growth front and depressions form at about $10^{9} \mathrm{~K} \cdot \mathrm{s} / \mathrm{m}^{2}$ of $G / R$, and funnel-like $\mathrm{L}_{2}$ droplets are incorporated into the aluminum matrix intermittently. These $L_{2}$ droplets spheroidize during cooling to form regular arrays of spherical $L_{2}$ droplets. The planar solid-liquid interface no longer lies at $G / R$ below $10^{9} \mathrm{~K} \cdot \mathrm{s} / \mathrm{m}^{2}$, and regular monotectic composite structures can not be formed. Droplet composite structures are also formed by necking down, pinching off and spheroidizing of $L_{2}$ fibers during cooling at high temperatures below the monotectic. The structural transition during cooling is enhanced, as the diameter of $\mathbf{L}_{2}$ fibers decreases, i.e., as growth rates increase.
\end{abstract}

(Received February 9, 1984)

Keywords: aluminum-indium alloy, monotectic reaction, unidirectional solidification, composite structures, solidification mechanism

\section{Introduction}

Solidified structures of monotectic Al-17.5 mass $\%$ In alloys solidified free-directionally and unidirectionally and their forming manner have been studied ${ }^{(1)(2)}$. Unidirectionally solidified structures of the alloys changed; fibrous composite of $\operatorname{In}\left(\mathrm{L}_{2}\right) \rightarrow$ periodical and regular array of $\operatorname{In}\left(\mathrm{L}_{2}\right)$ droplets $\rightarrow$ random dispersion of $\operatorname{In}\left(\mathrm{L}_{2}\right)$ droplets in the aluminum matrix with increasing growth rate and/or decreasing temperature gradient. This indicates that the structural transition depends on the ratio of temperature gradient $G$ to growth rate $R$. This also suggests that the transition of monotectic solidification structure has a closed relation to the morphological transition of solid-liquid interface.

Monotectic Al-17.5 mass \%In alloys were solidified unidirectionally at various growth

* This paper was originally published in Japanese in J. Japan Inst. Metals, 48 (1984), 84.

** Department of Metallurgical Engineering, Tokyo Institute of Technology, Tokyo 152, Japan.

*** Graduate Student, Tokyo Institute of Technology, Tokyo 152, Japan. rates and temperature gradients in the present work, and were quenched during growth to reproduce the monotectic growth front morphology. The morphology of $\mathrm{Al}$ solid phase and the dispersion behavior of In rich $\mathrm{L}_{2}$ phase at the monotectic growth front were examined. The forming manner of regular monotectic composite and its structural transition are discussed. The alloys having fibrous composite structures were held near the monotectic temperatures for various times, and the thermal stability of $\mathrm{L}_{2}$ fibers is also examined.

\section{Experimental Procedures}

The methods for alloy preparation and unidirectional solidification were described in the preceding paper ${ }^{(2)}$. Rapid cooling during the unidirectional growth was done in two different ways. In the first way, a graphite mold was set on a copper chill block. Unidirectional solidification of alloys was achieved by moving a tubular electric furnace upward. When the monotectic growth front reached the given position of C.A. thermocouple in a graphite mold cavity, the electric furnace was pulled up 
as quickly as possible, and the solidifying alloys were quenched into water together with the graphite mold. In the second way, unidirectional solidification was achieved by driving downward a high purity alumina crucible through an induction coil, and the crucible was pulled out from the heating zone, when the monotectic growth front reached the given position of C.A. thermocouple, and was cooled rapidly by air blowing.

Scanning electron microscopy and backscattering electron imaging were made for microstructural observation.

The fibrous composite structure was held at $903 \mathrm{~K}$ (9 K below the monotectic temperature) in the electric furnace for various time durations and quenched into water. The thermal stability of $L_{2}$ fibers was examined through micrography.

\section{Results and Discussion}

\section{Forming manner of fibrous composite structures}

When Al-17.5 mass \% In alloys are solidified unidirectionally at $G / R 10^{9} \mathrm{~K} \cdot \mathrm{s} / \mathrm{m}^{2}$ or more, fibrous composite structures, fine and regular alignment of $\mathrm{L}_{2}$ fibers (white phase) in the aluminum matrix (black phase) along the growth direction, are formed as shown in Fig. 1. The Al solid solution and the In rich $\mathrm{L}_{2}$ phase are serparated from $\mathrm{L}_{1}$ liquid simultaneously. This $L_{2}$ phase is kept in the liquid state even below the monotectic temperature down to $429.4 \mathrm{~K}$. In the figure, the fine $L_{2}$ droplets dispersion structure represents

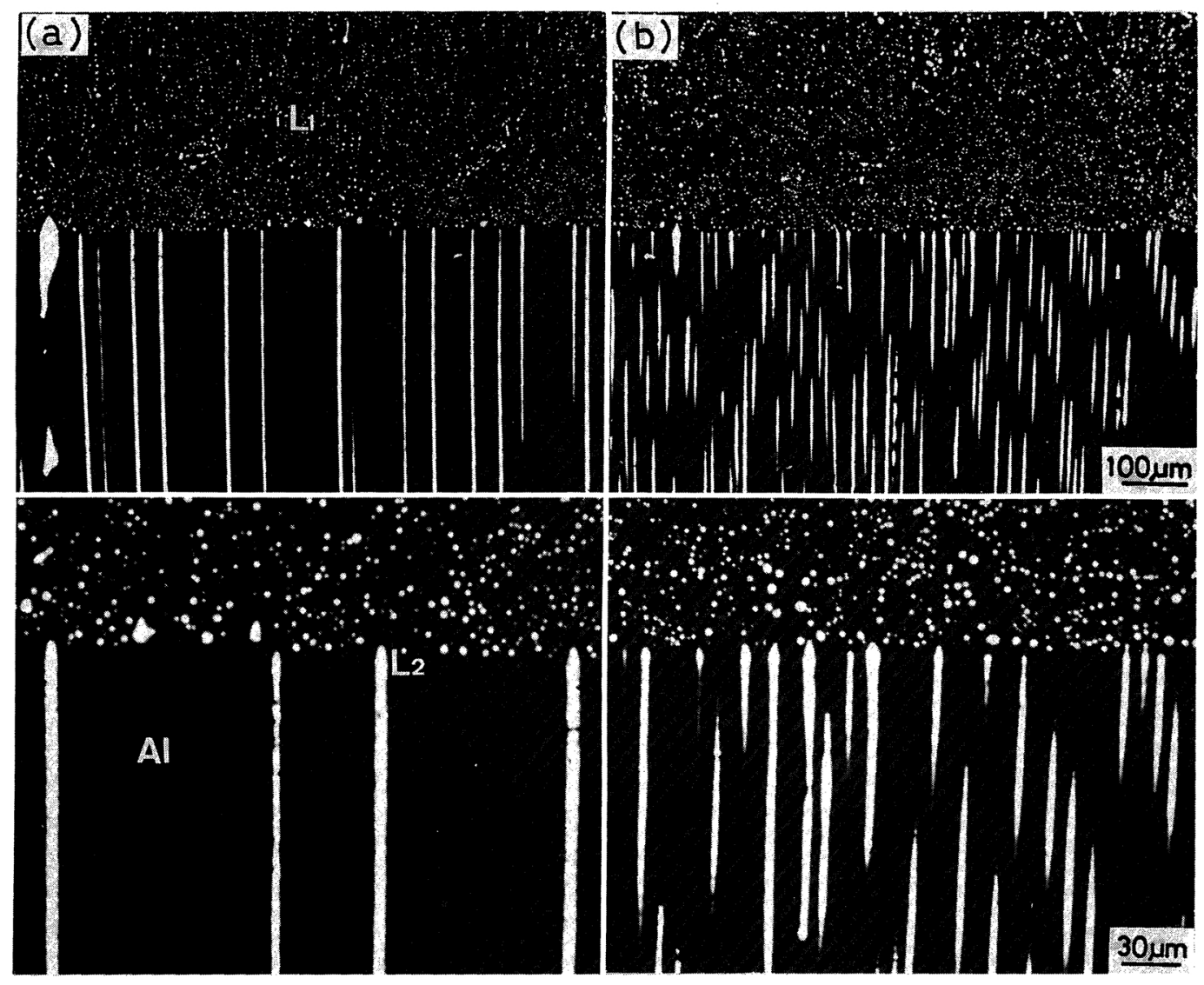

Fig. 1 Solid-liquid interface morphology of fibrous composite in $\mathrm{Al}-17.5$ mass \% In alloys solidified unidirectionally. (BEI)

(a) $G=2500 \mathrm{~K} / \mathrm{m}, R=0.28 \times 10^{-6} \mathrm{~m} / \mathrm{s}$ and $G / R=9 \times 10^{9} \mathrm{~K} \cdot \mathrm{s} / \mathrm{m}^{2}$.

(b) $G=6000 \mathrm{~K} / \mathrm{m}, R=3.6 \times 10^{-6} \mathrm{~m} / \mathrm{s}$ and $G / R=2 \times 10^{9} \mathrm{~K} \cdot \mathrm{s} / \mathrm{m}^{2}$. 
rapidly the cooled $L_{1}$ liquid ahead of the freezing interface, distinctly showing the topography of monotectic freezing interface. Figure 1(a) shows the structure solidified at the temperature gradient $G 2500 \mathrm{~K} / \mathrm{m}$, the growth rate $R 0.28 \times 10^{-6} \mathrm{~m} / \mathrm{s}$ and $G / R 9 \times 10^{9} \mathrm{~K} \cdot \mathrm{s} / \mathrm{m}^{2}$. (b) shows the structure solidified at $G 6000$ $\mathrm{K} / \mathrm{m}, R 3.6 \times 10^{-6} \mathrm{~m} / \mathrm{s}$, and $G / R 2 \times 10^{9} \mathrm{~K} \cdot \mathrm{s} / \mathrm{m}^{2}$. These large $G / R$ values exceeding $10^{9} \mathrm{~K} \cdot \mathrm{s} / \mathrm{m}^{2}$ result in a generally planar solid-liquid interface and aligned $L_{2}$ fibers. The $L_{2}$ liquid slightly projects into the melt. Coarser $\mathrm{L}_{2}$ phases, on the other hand, discontinuously lie along the growth direction at the monotectic cell boundaries. Fibrous composite structures are formed at high $G / R$ or under the growth condition for the stable planar solid-liquid

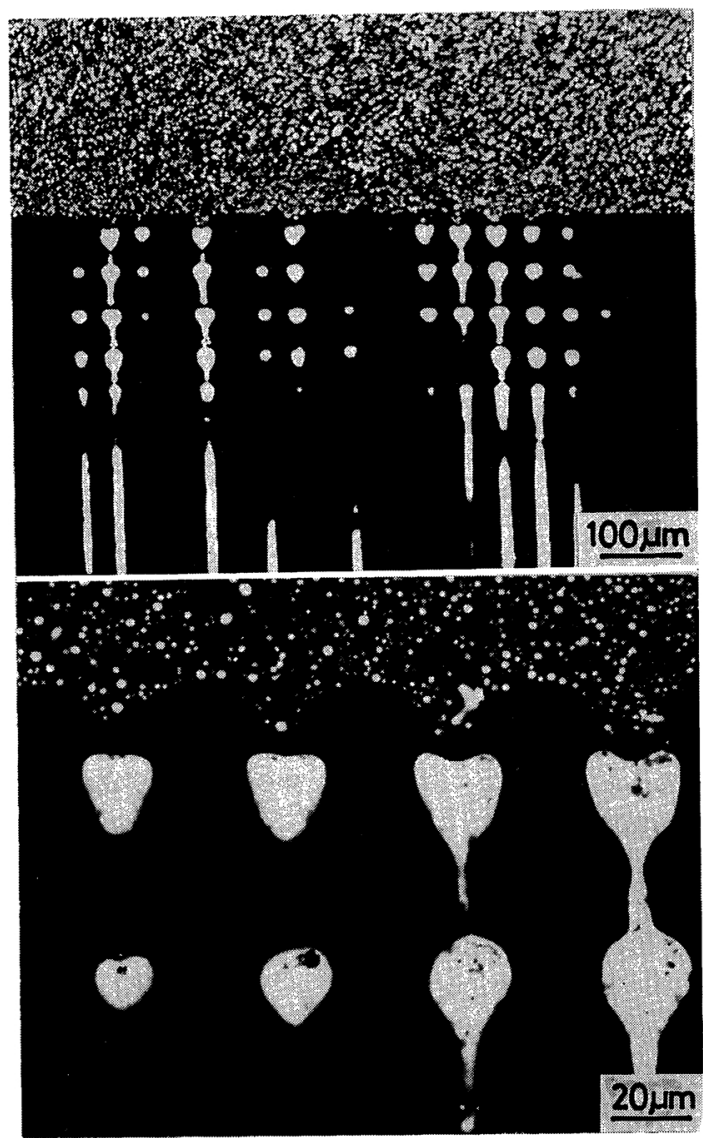

Fig. 2 Periodical fluctuation of solid-liquid interface and formation of array of $\mathrm{L}_{2}$ droplets. (BEI) $G=400 \mathrm{~K} / \mathrm{m}, R=0.44 \times 10^{-6} \mathrm{~m} / \mathrm{s}$ and $G / R=9 \times 10^{8}$ $\mathrm{K} \cdot \mathrm{s} / \mathrm{m}^{2}$. interface. The inter-fiber spacing $(\lambda)$ decreases with faster growth rate $(R)$, being related to $R$ by $\lambda=K R^{-1 / 2}$, which means that the formation of $\mathrm{L}_{2}$ fibers depends on the diffusion controlling process $^{(2)}$.

\section{Forming manner of droplet composite structures}

Figures 2 to 5 show the morphology of solidliquid interface obtained at $9 \times 10^{8} \mathrm{~K} \cdot \mathrm{s} / \mathrm{m}^{2}$ of $G / R$. The structural transition from fibrous composite to droplet composite occurs. When $L_{2}$ droplets are formed, the solid-liquid interface fluctuates finely and periodically, as $G / R$ lowers. The shape of $\mathrm{L}_{2}$ droplets is not globular but funnel-like in the vicinity of the growth front, as shown in Fig. 2. The Al solid slightly proceedes at $G / R$ up to $10^{9} \mathrm{~K} \cdot \mathrm{s} / \mathrm{m}^{2}$, forming depressions on the growth front. The funnel-

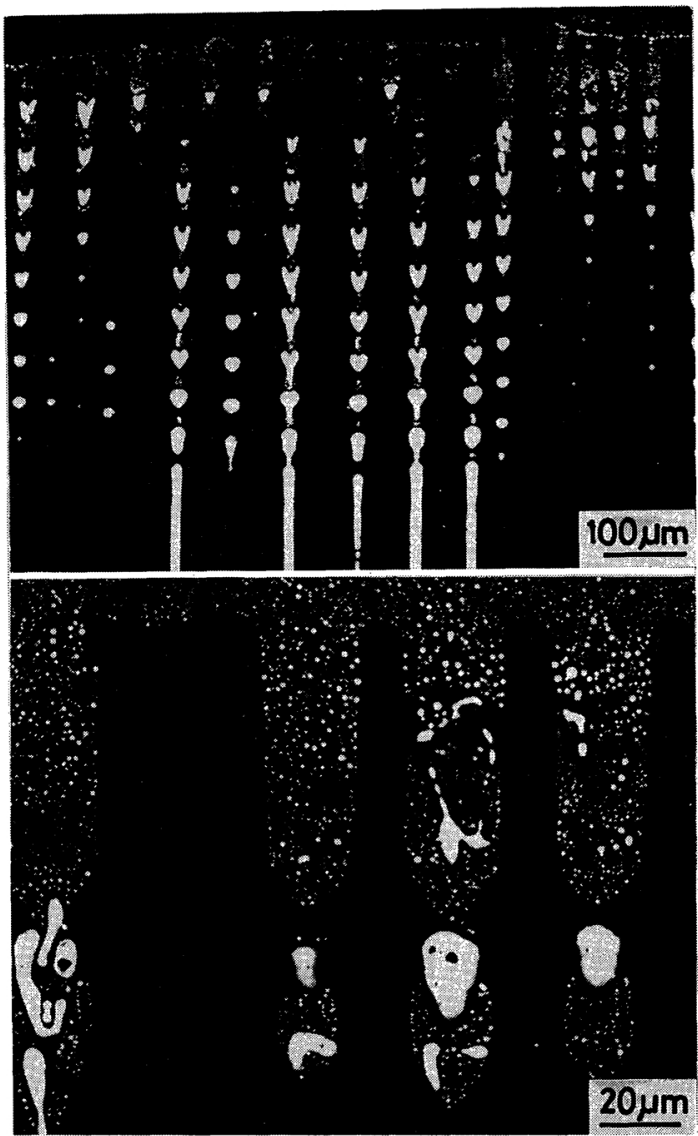

Fig. 3 Depression on solid-liquid interface and periodical formation of funnel-like $L_{2}$ phase. (BEI) 

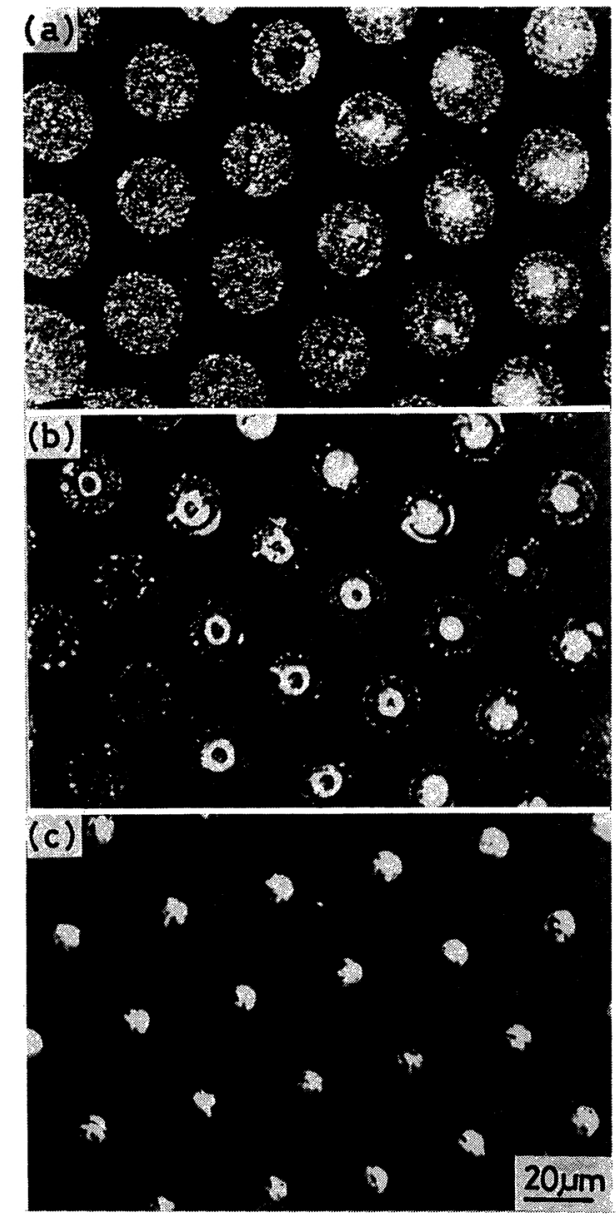

Fig. 4 Transverse section at solid-liquid interface. (BEI) The distance from the growth front increases in the sequence (a) $\rightarrow$ (b) $\rightarrow$ (c)

(a) Depression on the growth front.

(b) Funnel-like $\mathbf{L}_{2}$ droplets were formed in depressions.

(c) $\mathbf{L}_{2}$ droplets in an aluminum matrix.

like $\mathrm{L}_{2}$ liquid separated by the monotectic reaction intermittently aggregates in the depressions, as shown in Fig. 3. Indium is condensed to the upper side of the depression in the figure. The formation of depressions is attributed to the constitutional undercooling caused by enrichment of In into the liquid ahead of the growing interface of monotectic solidification. Transverse sections near the solid-liquid interface are shown in Fig. 4, in which depressions have been formed regularly on the monotectic growth front. When growth of the Al solid precedes coalescing of the $\mathrm{L}_{2}$ liquid, some fine

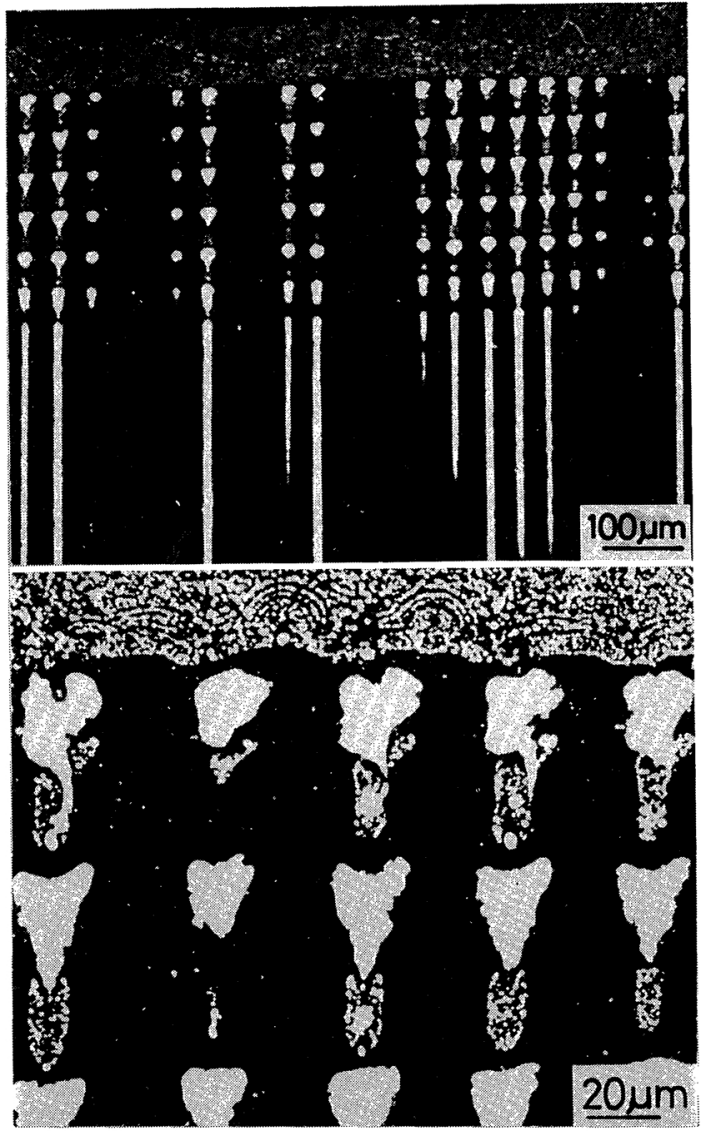

Fig. 5 Incorporation of coarser funnel-like $\mathbf{L}_{2}$ droplets and fine $\mathrm{L}_{2}$ droplets in growing $\mathrm{Al}$ matrix. (BEI)

$\mathrm{L}_{2}$ liquid clusters tend to be trapped in the $\mathrm{Al}$ solid, before the coalescence completes. Consequently, funnel-like $\mathrm{L}_{2}$ liquids and small liquid clusters coexist in the grooves, as shown in Fig. 5. It seems that during further cooling, small $\mathrm{L}_{2}$ liquids diffuse to the larger ones and disappear, and funnel-like $\mathrm{L}_{2}$ liquids coarsen and spheroidize to form the array of spherical $\mathrm{L}_{2}$ liquids. When the alloys shown in Fig. 5 is held at $903 \mathrm{~K}(9 \mathrm{~K}$ below the monotectic temperature) for $3.6 \mathrm{ks}(1 \mathrm{~h})$, small $\mathrm{L}_{2}$ clusters disappear, funnel-like $\mathrm{L}_{2}$ liquids spheroidize and the arrayed structure of globular $L_{2}$ droplets is formed, as shown in Fig. 6.

A slight decrease in $G / R$, as mentioned above, results in the periodical fluctuation of the solid-liquid interface and the formation of 


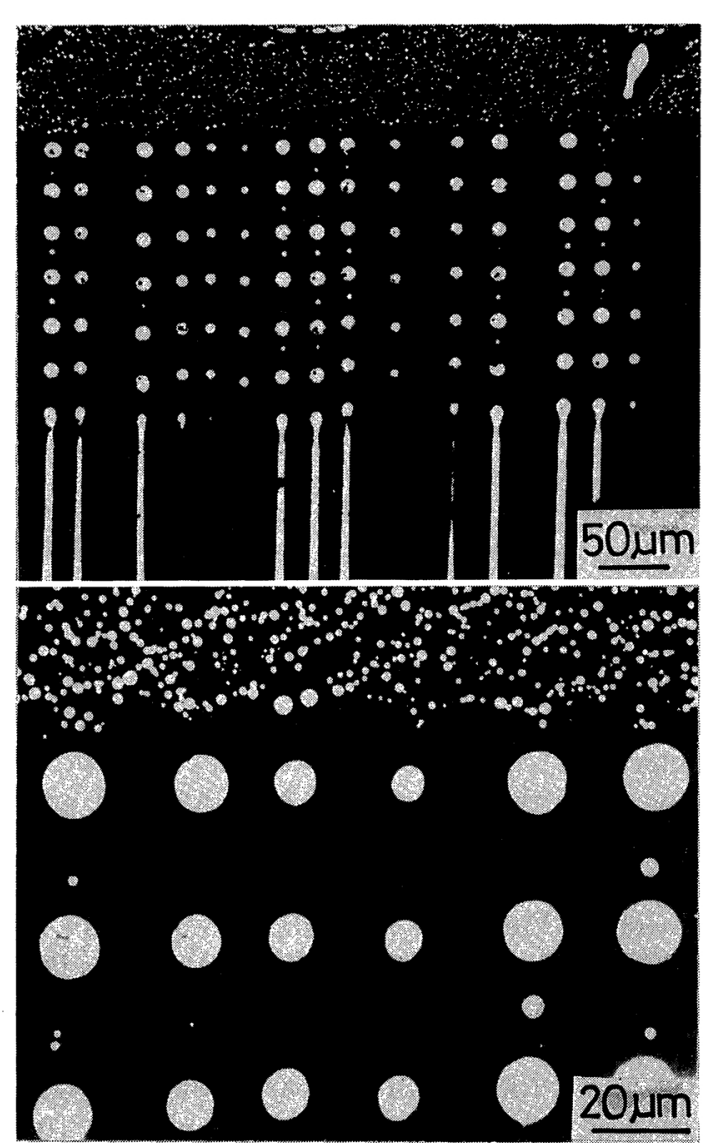

Fig. 6 Disappearance of fine $\mathbf{L}_{2}$ droplets and spheroidization of funnel-like $L_{2}$ droplets result in formation of arrayed droplets structure. (BEI) (after heating for $3600 \mathrm{~s}$ at $903 \mathrm{~K}$ )

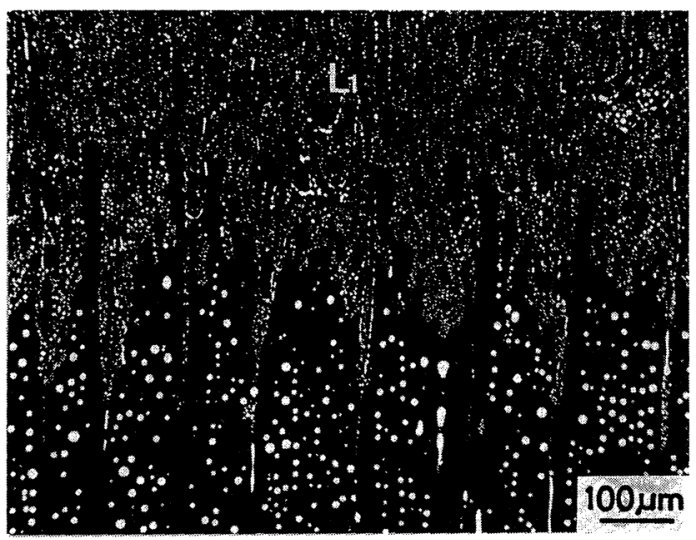

Fig. 7 Irregular growth front to form a random dispersion of $\mathrm{L}_{2}$ droplets at low $G / R$. (BEI)

depressions. The entrapped funnel-like $\mathrm{L}_{2}$ liquids and small $\mathrm{L}_{2}$ clusters in the grooves

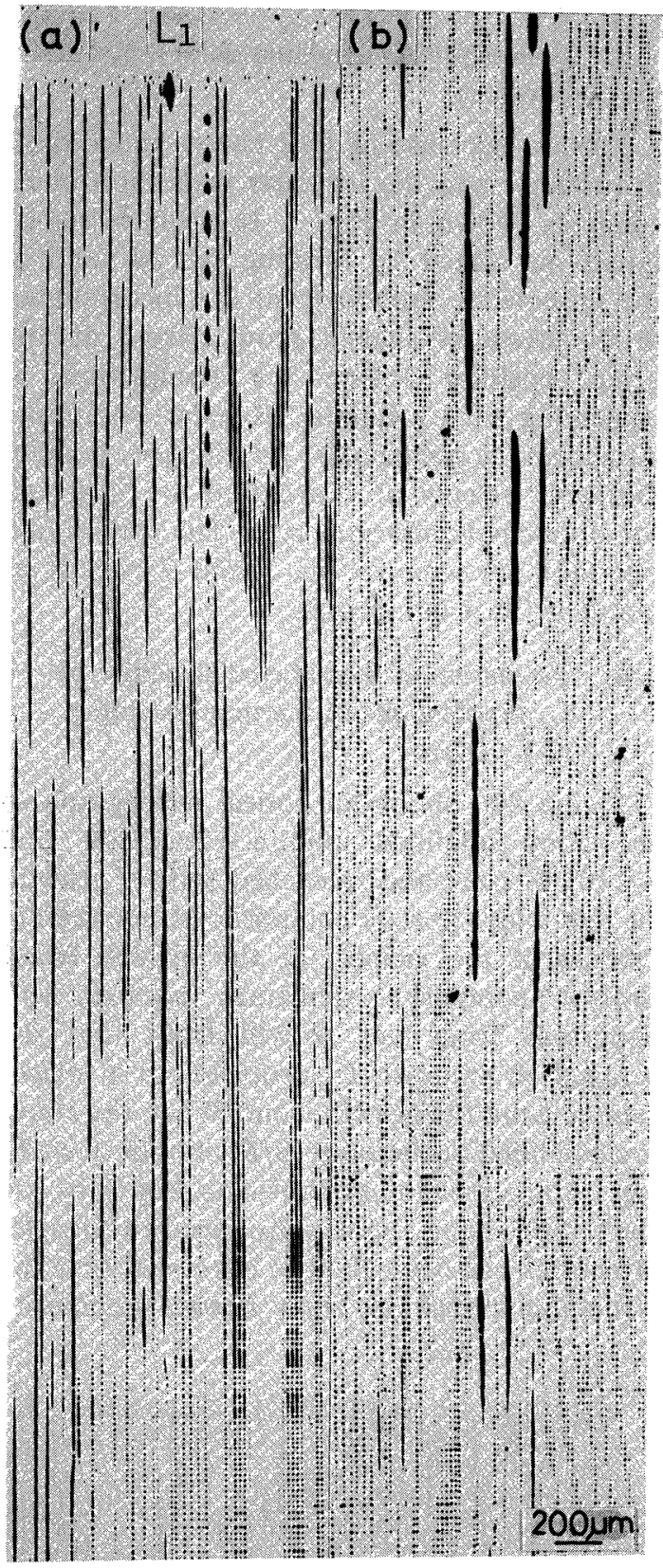

Fig. 8 Optical micrographs of unidirectionally solidified Al-17.5 mass $\%$ In alloys at $4 \times 10^{9} \mathrm{~K} \cdot \mathrm{s} / \mathrm{m}^{2}$ of $G / R$.

(a) Quenched during growth.

(b) Cooled down to room temperature.

coalesce mutually and spheriodize due to the interfacial energy balance to form the regularly arrayed structures of globular $\mathrm{L}_{2}$ droplets. 


\section{Disintegration of planar solid-liquid interface}

Further decrease of $G / R$ causes remarkable disturbance and the irregular projection of $\mathrm{Al}$ solid, as shown in Fig. 7. In such cases, $L_{2}$ liquids separated by forming the $\mathrm{Al}$ solid at the monotectic growth front are incorporated in the irregular shaped growth front at any given position before the completion of coalescing of $\mathrm{L}_{2}$ liquids. Regular composite structures consequently no longer remain. Different extents of fluctuation are observed for different monotectic cells. The solid-liquid interfaces shown in Figs. 5 and 7 coexist at about $10^{9} \mathrm{~K} \cdot \mathrm{s} / \mathrm{m}^{2}$ of $G / R$.

\section{Formation of the arrayed structure of $L_{2}$ droplets due to thermal instability of $\mathrm{L}_{2}$ fibers}

Figure 8(a) shows an optical micrograph of the alloy solidified unidirectionally at $G / R$ $4 \times 10^{9} \mathrm{~K} \cdot \mathrm{s} / \mathrm{m}^{2}$ and quenched during growth. In this alloy, fibrous composite structures are formed in the vicinity of the growth front, droplet composite structures coexist with departure from the growth front and the arrayed structure of $\mathrm{L}_{2}$ droplets lies at places remote from the growth front. When the alloys are solidified at the same $G / R$ without quenching during growth, as shown in Fig. 8(b), on the other hand, uniformly arrayed droplet structures are formed. It is suggested that the structural transition from fibrous composite to droplet composite structures may take place during cooling below the monotectic temperature. This transition is more significant in the alloy solidified at higher growth rates and has finer fibers.

The alloys having fibrous composite structures solidified in various growth conditions were held at $903 \mathrm{~K}(9 \mathrm{~K}$ below the monotectic temperature) for $1.8,3.6,7.2,10.8$ and 14.4 ks. Figure 9 shows a typical structural change. $L_{2}$ fibers neck down, pinch off and spheroidize to form globular $\mathrm{L}_{2}$ droplets. $\mathrm{L}_{2}$ droplets are regularly arrayed parallel and vertical to the growth direction. Figure 10 shows the time duration for the structural transition from $L_{2}$ fibers to $L_{2}$ droplets by heating at $903 \mathrm{~K}$. The thermal instability of fibrous composite structures depends on the inter-fiber spacing and the diameter of $\mathrm{L}_{2}$ fibers. As the growth rate increases, the interfiber spacing and the diameter of $\mathrm{L}_{2}$ fibers decrease, and the thermal stability is also lowered. Finer fibrous composites $(\lambda=17.5 \times$ $10^{-6} \mathrm{~m}, d=3.3 \times 10^{-6} \mathrm{~m}$ ) grown at $3.6 \times 10^{-6}$ $\mathrm{m} / \mathrm{s}$, for instance, change into the arrayed droplet structures as shown in Fig. 9 by heating for $1.8 \mathrm{ks}(0.5 \mathrm{~h})$, while coarser ones $(\lambda=33 \times$ $\left.10^{-6} \mathrm{~m}, d=8 \times 10^{-6} \mathrm{~m}\right)$ grown at $0.28 \times 10^{-6}$ $\mathrm{m} / \mathrm{s}$ take $14.4 \mathrm{ks}(4 \mathrm{~h})$ for their structural change. This suggests that finer fibers composite structures formed at higher growth rates change into arrayed droplet structures more easily as compared with coarser ones solidified at lower growth rates. Even if the fibrous composite

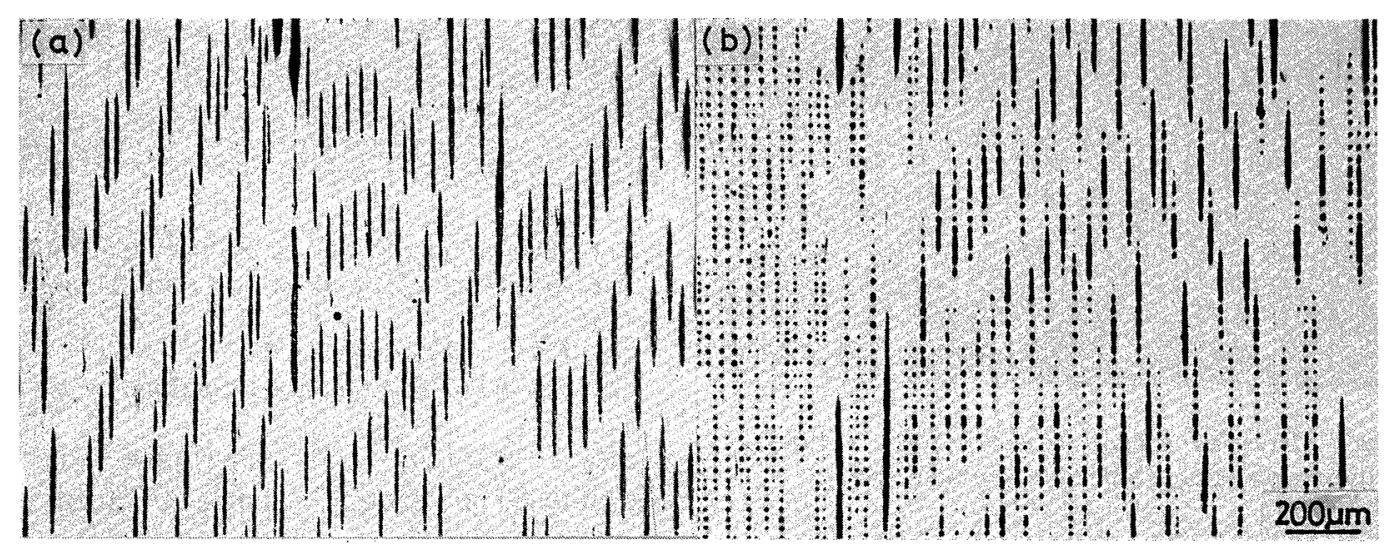

Fig. 9 Necking down, pinching off and spheroidizing of $\mathbf{L}_{2}$ fibers after heating. 


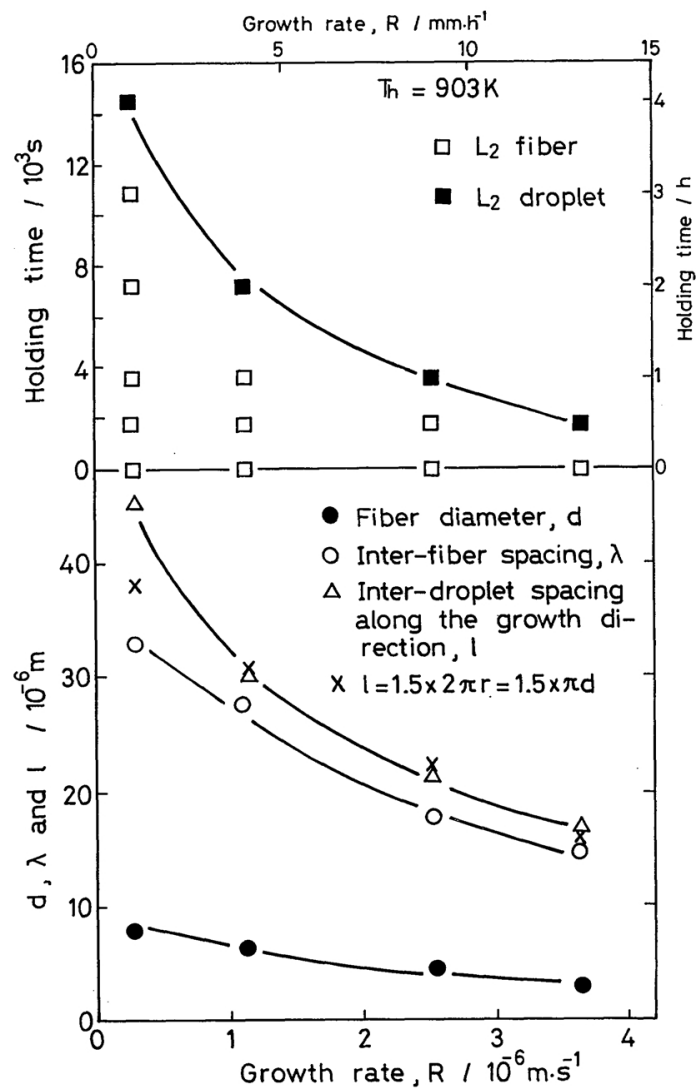

Fig. 10 The dependence of thermal stability of $\mathbf{L}_{2}$ fibers upon fiber diameter and inter-fiber spacing.

structures are formed by the monotectic solidification, necking down, pinching off and spheroidizing of $\mathrm{L}_{2}$ fibers take place during cooling below the monotectic temperature to form the arrayed droplet structures. $L_{2}$ fibers having the large diameter are thermally stable and remain unchanged.

Marinis and Sekerka ${ }^{(3)}$ calculated the instability of cylindrical fibers in a directionally solidified eutectic on the basis of their model newly proposed ignoring strain and anisotropy effects. They described that fiber shape perturbations with the wavelength less than the fiber circumference decayed, while perturbations of wavelength 1.5 times as large as the circumference exhibited the fastest growth rate. The inter-droplet spacing along the growth direction of $L_{2}$ droplets $(\triangle)$ formed by thermal treatments in the present work is considered to correspond to the thermal instability wavelength of $L_{2}$ fibers. The spacing $(\triangle)$ is in good agreement with the theoritical values $(x)$ obtained from the relationship $l=1.5 \times \pi d(l$; wavelength of perturbation and $d$; fiber diameter), as shown in Fig. 10.

\section{Classification of the monotectic solidification structures}

Grugel and Hellawell ${ }^{(4)}$ solidified Al-In alloys unidirectionally at various growth rates under $19000 \mathrm{~K} / \mathrm{m}$ of temperature gradient. They described that the fibrous composite structures, arrayed structures of $\mathrm{L}_{2}$ droplets and random dispersion of $L_{2}$ droplets are formed at growth rates $<5 \times 10^{-6}, 5$ to $10 \times$ $10^{-6}$ and $10 \times 10^{-6} \mathrm{~m} / \mathrm{s}$ or more, respectively. They also described that the arrayed structures of $\mathrm{L}_{2}$ droplets are never formed by structural change after monotectic solidification and it is attributed to the somewhat periodical fluctuation of solid-liquid interface. They classified monotectic solidification structures only by observing finally solidified structures and never considered the structural change from fiber to droplet during cooling below the monotectic temperature as shown in the present work. It is considered that the regular composite structure was achieved in their work at growth rates up to $10 \times 10^{-6} \mathrm{~m} / \mathrm{s}$, because the high temperature gradient $19000 \mathrm{~K} / \mathrm{m}$ resulted in the stable solid-liquid interface necessary for the formation of the regular composite structures even at high growth rates. $L_{2}$ fibers formed at higher growth rates are thermally unstable to change into the array of $\mathrm{L}_{2}$ droplets during cooling below the monotectic temperature. The arrayed droplet structures may be observable in finally solidified alloys grown at 5 to $10 \times 10^{-6} \mathrm{~m} / \mathrm{s}$.

According to the facts mentioned above, the forming manner of monotectic solidification structures is classified, as shown in Fig. 11. Here;

(A): The fibrous composite structure whose $\lambda$ and $d$ are large. This structure is obtained at high $G / R 10^{9} \mathrm{~K} \cdot \mathrm{s} / \mathrm{m}^{2}$ or more, which secures the planar monotectic growth front.

(B): The fibrous composite structure is once obtained through the monotectic solidification. The structure changes into the arrayed 


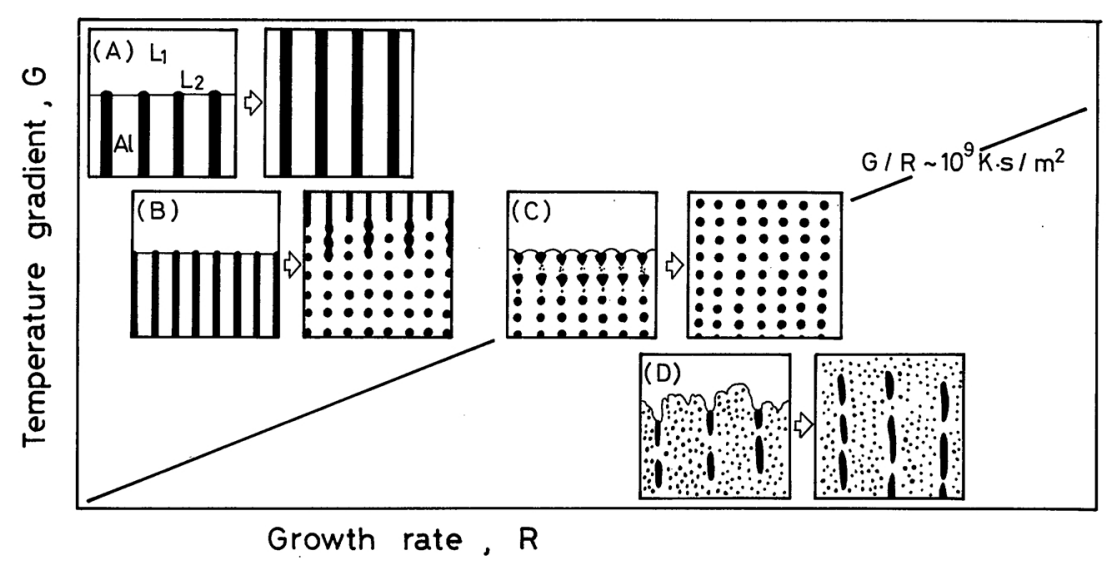

Fig. 11 Forming manner of monotectic composite at various $G / R$ values is illustrated schematically.

structure of $\mathrm{L}_{2}$ droplets in the course of cooling below the monotectic temperature.

(C): Periodical fluctuation takes place at the monotectic growth front to form the array of $\mathrm{L}_{2}$ droplets at $G / R$ about $10^{9} \mathrm{~K} \cdot \mathrm{s} / \mathrm{m}^{2}$.

(D): The planar solid-liquid interface disintegrates, and irregular projection of $\mathrm{Al}$ solid takes place. Fine $\mathrm{L}_{2}$ droplets consequently disperse at random in the aluminum matrix.

\section{Summary}

Monotectic Al-17.5 mass \%In alloys were solidified unidirectionally under various growth conditions and were quenched during growth to reveal the solid-liquid interface morphology. Fibrous composite structures are obtained at $G / R 10^{9} \mathrm{~K} \cdot \mathrm{s} / \mathrm{m}^{2}$ or more. When the structures are forming, the planar solid-liquid interface proceeds with some projection of $\mathrm{L}_{2}$ phase toward $\mathrm{L}_{1}$. Periodical fluctuation of the growth front and depressions form at about $10^{9} \mathrm{~K} \cdot \mathrm{s} / \mathrm{m}^{2}$ of $G / R$, and funnel-like $\mathrm{L}_{2}$ droplets are incorporated into the aluminum matrix intermittently. These $L_{2}$ droplets spherodize during cooling to form regular arrays of spherical $\mathrm{L}_{2}$ droplets. The planar solid-liquid interface no longer lies at $G / R$ below $10^{9} \mathrm{~K} \cdot \mathrm{s} / \mathrm{m}^{2}$, and regular monotectic composite structures can not be formed. $\mathrm{L}_{2}$ fibers formed at the monotectic growth front neck down, pinch off, spherodidize and change into the array of $\mathrm{L}_{2}$ droplets. This structural transition is significant in the $L_{2}$ fibers of small diameter. The arrayed droplet structure can be formed in two different ways. It is directly formed in the first way through the monotectic solidification at the critical $G / R$ approximately $10^{9} \mathrm{~K} \cdot \mathrm{s} / \mathrm{m}^{2}$. It is also formed indirectly in the second way through the structural change of $\mathrm{L}_{2}$ fibers in the course of cooling after the completion of monotectic reaction.

\section{Acknowledgement}

This work was supported in part by a Grantin-Aid for Scientific Research from the Ministry of Education, Science and Culture, Japan.

\section{REFERENCES}

(1) A. Kamio, H. Tezuka, S. Kumai and T. Takahashi: J. Japan Inst. Metals, 46 (1982), 1200 (in Japanese).

(2) A. Kamio, H. Tezuka, S. Kumai and T. Takahashi: J. Japan Inst. Metals, 48 (1984), 78 (in Japanese).

(3) T. F. Marinis and R. F. Sekerka: Material Research Society Meeting of November (1978).

(4) R. N. Grugel and A. Hellawell: Met. Trans., 12A (1981), 669. 